\title{
Identification and Characterization of Gene Expression Involved in the Coloration of Cichlid Fish Using Microarray and qRT-PCR Approaches
}

\author{
Helen M. Gunter • Céline Clabaut • \\ Walter Salzburger $\cdot$ Axel Meyer
}

Received: 4 November 2010/ Accepted: 3 January 2011/Published online: 26 January 2011

(C) Springer Science+Business Media, LLC 2011

\begin{abstract}
It has been suggested that speciation on the basis of sexual selection is an important mechanism for the generation of new species for East African cichlids, where male body coloration is one of the major discriminatory factors used by females in mate choice. To gain insight into the molecular basis of cichlid coloration, we studied the Lake Malawi cichlid Pseudotropheus saulosi, comparing transcription in the bright blue skin of males to the yellow skin of females. Our cDNA microarray experiments identified 46 clones that exhibited expression differences between the two sexes, of which five were confirmed to be differentially expressed by relative quantitative real-time PCR (qRT-PCR). This gene list includes a representative from the endosomal-to-Golgi vesicle trafficking pathway, Coatomer protein complex, subunit zeta-1 (Copz-1), which
\end{abstract}

Electronic supplementary material The online version of this article (doi:10.1007/s00239-011-9431-x) contains supplementary material, which is available to authorized users.

H. M. Gunter · C. Clabaut · W. Salzburger · A. Meyer ( $\square)$

Lehrstuhl für Zoologie und Evolutionsbiologie,

Department of Biology, University of Konstanz,

Universitätsstr. 10, 78457 Constance, Germany

e-mail: axel.meyer@uni-konstanz.de

H. M. Gunter

Zukunftskolleg, University of Konstanz, Universitätsstr. 10,

78457 Constance, Germany

Present Address:

C. Clabaut

Department of Organismic and Evolutionary Biology, Harvard

University, 16 Divinity Ave., Cambridge, MA 4105, USA

Present Address:

W. Salzburger

Zoologiches Institut, Universität Basel, Vesalgasse 1,

4051 Basel, Switzerland is known to be a critical determinant of pigmentation in humans and zebrafish. With the support of microscopic images of the skin of these specimens, we interpret the transcriptional differences between the blue males and yellow females. Here, we provide insight into the putative functional diversification of genes involved in the coloration of cichlids and by extension, on the evolution of coloration in teleost fish.

Keywords Adaptive evolution - Cichlid species flocks . Sexual selection $\cdot$ Copz $\cdot$ Collagen 1 alpha

\section{Introduction}

The family Cichlidae is composed of about 3,000 species, making it one of the most species-rich families of vertebrates. More than 1,500 endemic species alone live in the Great Lakes of Eastern Africa. Because of their impressive phenotypic diversity, their extremely fast speciation rates, and their unique degree of endemism, cichlid fishes have attracted the attention of researchers from several biological sub-disciplines. African cichlids have become a prime model system for the study of evolutionary processes, especially for explosive rates of speciation, the formation of adaptive radiations and a multitude of mechanisms of speciation (Fryer and Iles 1972; Meyer 1993; Kocher 2004; Salzburger and Meyer 2004; Elmer et al. 2009a, b).

The evolutionary success of the East African cichlids has been attributed to a combination of ecological opportunities (after the colonization of large lakes), and behavioral (maternal mouthbrooding), and morphological innovations (egg-spots, color polymorphisms, and pronounced sexual dichromatism) (Fryer and Iles 1972; Meyer 1993; Galis and Metz 1998; Kocher 2004; Salzburger et al. 2005; Elmer 
et al. 2009b). Sexual selection has been proposed as an important mechanism in their speciation. This has been demonstrated by field observations (van Oppen et al. 1998; Salzburger et al. 2006; Elmer et al. 2009b) and complementary mate choice experiments in the laboratory (Barlow et al. 1977, 1990; Knight et al. 1998; Seehausen et al. 1999). More specifically, ecological evidence that sexual selection plays a role in speciation came from the inferred breakdown of visual reproductive barriers under monochromatic light conditions or in turbid waters (Seehausen et al. 1997; Seehausen et al. 2008). Recent research on visual pigments has added to these observations and suggests that the way in which cichlids perceive the world visually changes rapidly throughout evolution and development (Carelton et al. 2008; Hofmann et al. 2009) and ultimately modifies their ability to discriminate potential mates. Taken together, these results suggest that male body hue is one of the primary discriminatory factors among a hierarchy of visual and probably olfactory cues used by females.

In cichlids, it has been shown that species with highly similar colors have evolved repeatedly within and among lakes, with a predominance of blue and yellow colors (Meyer 1993; Stiassny and Meyer 1999; Seehausen et al. 1999; Seehausen and van Alphen 1999; Allender et al. 2003; Elmer et al. 2010). This has resulted in astonishing phenotypic diversity despite their genetic uniformity due to their extremely young age (Meyer et al. 1990; Sturmbauer and Meyer 1992; Allender et al. 2003; Verheyen et al. 2003). Furthermore, body color differences evolved intraspecifically and a rich palette of color polymorphisms is known from cichlid assemblages in the New as well as the Old World. These color morphs can be so strikingly different that the casual observer would assign them to different species (Fryer and Iles 1972). Finally, many cichlid species, and in particular the modern haplochromine cichlids, are sexually dichromatic, with the male being the colorful sex and females typically having a dull cryptic body color (Salzburger et al. 2005).

Coloration in vertebrates is based on the number and distribution of three types of pigment cells (chromatophores): dark melanophores, yellow to orange xanthophores, and reflective iridophores, responsible for a white or silvery coloration (Bagnara and Hadley 1973; Fujii 1993a, 2000; Mellgren and Johnson 2002; Braasch et al. 2008). In teleost fishes, at least two more classes of chromatophores have been identified: the white leucophores and the blue cyanophores (Bagnara 1998). The chromatophores originate from neural crest cells that migrate in the ectoderm of the embryo during early ontogeny (Bagnara et al. 1979).

Each chromatophore has a characteristic set of pigments that reside in special pigmentary organelles (Fujii 1993a, b; Bagnara 1998). These organelles are described as melanosomes, which contain melanin in melanocytes (Charles and Ingram 1959; Drochmans 1960; Birbeck 1963); pterinosomes, which contain pteridines in xanthophores (Matsumoto 1965a; Kamei-Takeuchi and Hama 1971; Bagnara 1976); and the reflective platelets, which contain purines in iridophores (Bagnara and Stackhouse 1961; Bagnara et al. 1979). Pterinosomes and melanosomes are derived from the Golgi complex (Obika 1993). They contain a species-specific set of pteridines that appear at the same ontogenetic stage as when xanthophores undergo differentiation (Matsumoto et al. 1960; Hama 1963; Obika 1963; Matsumoto 1965b). Sepiapterins, drosopterins, and several colorless pteridines can be detected as yellow pigmentation that first becomes visible within pterinosomes (Obika 1963; Kamei-Takeuchi and Hama 1971).

Determining the genetic mechanisms that drive the evolution of cichlid color patterns will aid in the understanding of their explosive speciation. As cichlids experienced the fish-specific genome duplication the increased number of genes, followed by lineage-specific gene loss, sub-functionalization and regulatory evolution might be a genomic explanation for their species richness (Taylor et al. 2001a, b; Santini et al. 2003; Braasch et al. 2006, 2007, 2008, 2009a, b, c). The utility of the cichlid genome has increased in recent years and is coordinated by the cichlid genome consortium (http://cichlid.umd.edu/CGC index.html), which has developed genetic linkage maps (Kocher et al. 1998; Albertson et al. 2003; Sanetra et al. 2009), BAC libraries (Katagiri et al. 2001; Watanabe et al. 2003; Lang et al. 2006), cDNA and EST libraries (Watanabe et al. 2004; Salzburger et al. 2008), and microarrays (Renn et al. 2004). Genomic tools have previously been used to successfully identify the genetic basis of sex-biased coloration in cichlid fishes. For example, QTL analysis has identified that the genetic basis of the orange blotch color pattern in Lake Malawi cichlid fishes is a mutation in the cis-regulatory region of the $\operatorname{Pax} 7$ gene, which results in a significant increase in expression of this gene (Streelmann et al. 2003; Roberts et al. 2009).

It stands to reason that other regulatory changes underlying cichlid color polymorphisms might be rapidly identified using genome-wide transcription-profiling techniques such as DNA microarray. DNA microarray technology permits genome-wide comparisons of gene expression in different tissues or developmental stages, in healthy or diseased individuals, and in response to different environmental conditions (see, e.g., Crawford et al. 1999; Gasch et al. 2000; Michaut et al. 2003; Segal et al. 2003; Whitehead and Crawford 2005; Abzhanov et al. 2006). This is achieved through the hybridization of labeled RNAs to slides that have been "spotted" with cDNA clones from a given organism. The relative transcription can be calculated for given samples, through comparing the intensity of 
labeling at any given "spot." Here, we investigated the genetic basis of color polymorphism in a cichlid species using an approach that combines microarray and relative quantitative real-time PCR (qRT-PCR) with morphological investigations.

We examined the transcriptional basis of sexually dimorphic coloration in the Lake Malawi cichlid Pseudotropheus saulosi (PS). Our examination compared the expression of $\sim 6000$ clones from the blue skin of a PS male (Fig. 1a) to the yellow skin of a PS female (Fig. 1b), using a cDNA microarray chip. This chip was constructed using sequenced ESTs from the "pinky" library, derived from a range of tissues including the skin of the African cichlid Astatotilapia burtoni (AB), detailed in Salzburger et al. (2008). AB and PS are closely related and it has been shown that heterologous microarray hybridization can yield biologically meaningful data even in much more distantly related species (Renn et al. 2004; Cummings et al. 2008). After identifying the genes that showed a difference in expression between skin samples of the different color morphs of PS, we used qRT-PCR to confirm and expand upon the results of the microarray experiments. We also analyzed the expression of the previously isolated color genes csflra and csflrb, as csflra is important to xanthophore cell fate and is known to be expressed in the yellow egg dummies of African cichlids (Williams et al. 2002a, b; Parichy and Turner 2003; Braasch et al. 2006; Salzburger et al. 2007).

\section{Materials and Methods}

\section{Tissue Samples}

A single brood of PS was reared in a single tank, under standard conditions $\left(12 \mathrm{~h}\right.$ light; $12 \mathrm{~h}$ dark, $25^{\circ} \mathrm{C}$ water temperature). Adult fish were killed after anesthetizing them with Tricaine (MS222; Sigma) and were frozen in liquid nitrogen and stored at $-80^{\circ} \mathrm{C}$. Colored skin pieces of $1.0 \mathrm{~cm} \times 0.5 \mathrm{~cm}$ were later removed from the bright blue (males) and yellow (females) (Fig. 1a, b; Supplementary Fig. S1) from regions adjacent to one of the dark bands on the central part of the fish's flank. Scales were left on the skin samples because their removal destroys most of the chromatophores (data not shown). We used fluorescent microscopy methods to detect xanthophores in these samples (see Odenthal et al. 1996). The skin was mounted in methyl cellulose with 1 drop of $0.2 \% 3$-aminobenzoic acid ethyl ester (Sigma) and 1 drop of dilute ammonia, $0.1 \%$ $\beta$-mercaptoethanol, $\mathrm{pH}$ 10.0. Pictures were taken under transmitted light and UV light (DAPI-filter) with an Axiophot 2 microscope (Zeiss). The dilute ammonia liberates pteridines from their protein carriers at a high $\mathrm{pH}$. These are then visualized as light green fluorescence (Epperlein and Claviez 1982; Odenthal et al. 1996).

RNA was purified from skin samples from the flanks of 10 males and 9 females of identical sizes and locations to those used for the histology analysis (Supplementary Fig. S1). Total RNA was purified using TRIZOL LS (Life Technologies) according to the manufacturer's instructions. Purified RNA was resuspended in RNase-free water. The concentration of total RNA was calculated with an Eppendorf Biophotometer 6131, and the quality was assessed through agarose gel electrophoresis. First strand cDNA was synthesized from $5 \mu \mathrm{g}$ of total RNA of each sample, using Superscript III Reverse Transcriptase (Invitrogen), primed by oligo $\mathrm{d}(\mathrm{T})$. To test for genomic DNA contamination, cDNA was used for PCR amplifications of gapdh and actin genes that spanned at least one intron (see Supplementary Table S1).

\section{Hybridization Experiments}

Here, we used a microarray generated from a normalized cDNA library derived from whole "pinky" juveniles of the African cichlid Astatotilapia burtoni (Salzburger et al. 2008). Scienion (Berlin, Germany) performed the spotting; where 1-3 ng of each clone was applied to the chips, in addition to a 96-well "control plate." In total, the array contained 6,144 spots from the A. burtoni EST library, with an average length of $615 \mathrm{bp}$. The control plate contained fragments of 12 candidate "color" genes that were isolated from cDNA of A. burtoni, in duplicate and water blanks. The candidate color genes include pdgflba, pdgflbb, csflra, csflrb, endrbl, wntl, kita, aiml, mclr, soxlob, from previously published sequences (Braasch et al. 2006; Lang et al. 2006; Salzburger et al. 2007), plus pax3. Hybridization probes were generated from pooled cDNA synthesized from a total of $15 \mu \mathrm{g}$ of total RNA extracted from three different individuals for each sex. The hybridization probes were labeled using the Labelstar Array kit (Qiagen) with FluoroLink Cy 3-dCTP and Cy 5-dCTP (Amersham Biosciences) according to the manufacturer's protocol. The labeled cDNAs were hybridized to the chips at $60^{\circ} \mathrm{C}$ for 16-21 h, washed with SSC buffer, and read with a Genepix 4000B microarray reader (Axon Instruments). Three arrays (an array used later as reference array and two dye-flip replicates of it) were used to examine all spotted cDNAs as uneven background fluorescence obscured some of the spots. The dye-flip (also known as dye swap or reverse labeling) technique generates paired slides where, on the first slide, one mRNA sample is labeled by Cy5 and the other mRNA sample is labeled by $\mathrm{Cy} 3$, while, on the second slide, the labels for the two samples are exchanged. This technique removes dye-specific effects (Sartor et al. 2003; Yongxiang Fang et al. 2003). 

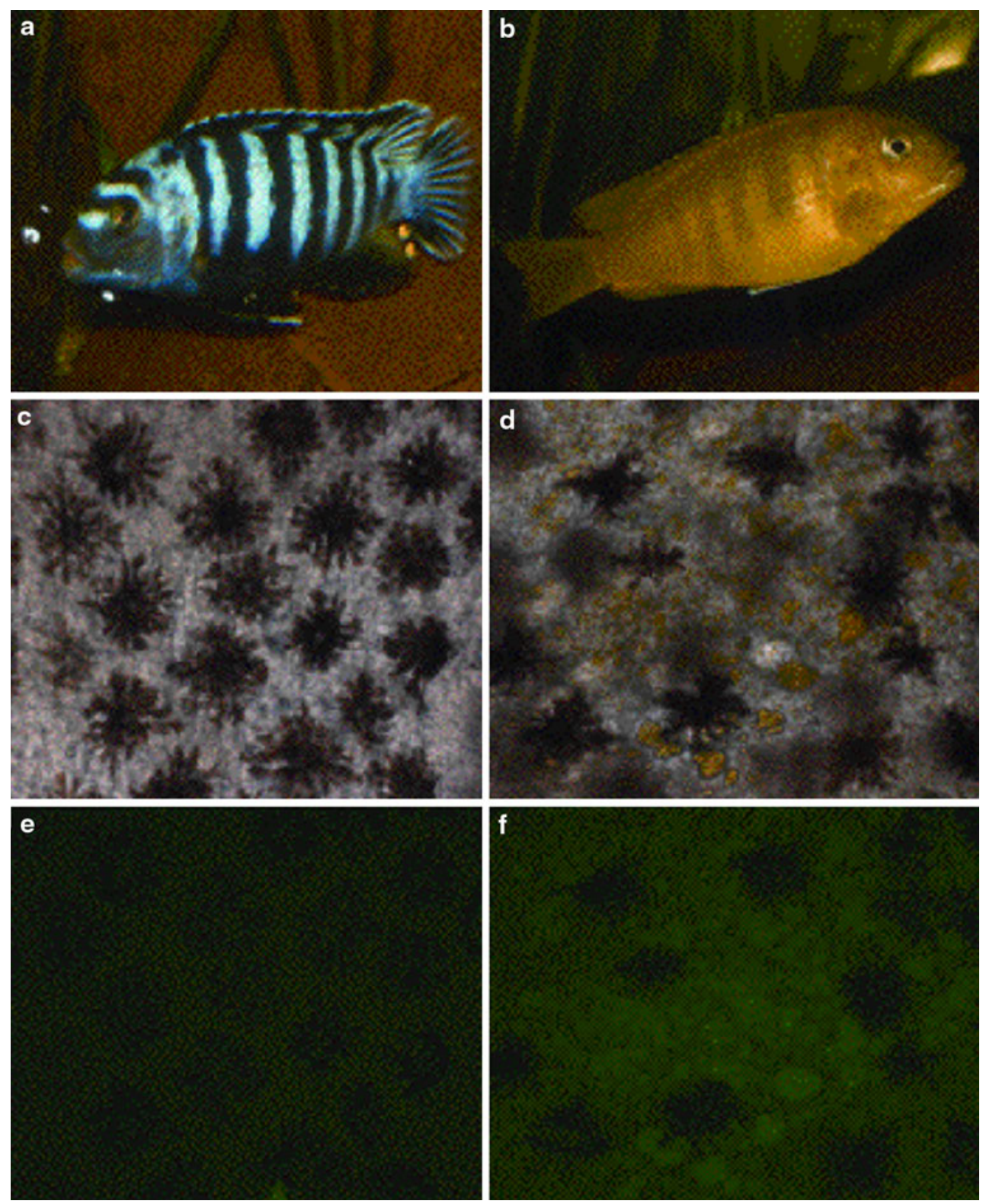

Fig. 1 Images of fish and their skin under transmitted light and UV light. a PS male, b PS female, $\mathbf{c}$ skin of PS male under transmitted light, d skin of PS female under transmitted light, e skin of PS male under UV light, and $\mathbf{f}$ skin of PS female under UV light

\section{Analysis}

After normalization (performed with the Genepix Pro 4.0 software on the basis of the mean of the intensities ratios), 2,196 of the spots showed a difference in expression in at least one dye-flip experiment. From this list, we identified the spots that showed a difference in their log ratios of intensities that was above 2-fold, between the reference array and at least one of the dyeflip experiments. The reliability of the genes in the microarray list was tested through qRT-PCR. Additionally, we analyzed the expression of csflra and $c s f 1 r b$, as csflra is known to be strongly expressed during the specification of yellow egg spots in cichlid fishes (Salzburger et al. 2007).

\section{qRT-PCR Experiments}

For the selected 46 clones, sequences were obtained using the original insert from the cDNA library amplified with primers SP6 and T7 (see Supplementary Table S1) using an ABI PRISM 3100 sequencer (Applied Biosystems). Of the 46 clones, all contained unique sequences except for 04C E05 and 14C E03, as determined through alignment with Sequencher 4.0 (10\% minimum overlap), thus expression analysis of this gene (parvalbumin beta) is 
based on primers designed to 04C E05 only. Specific primers for each unique clone and for csflra and csflrb (see Supplementary Table S1) were then designed using Primer Express (Applied Biosystems).

For the qRT-PCR experiment, fresh RNA was extracted from the skin of four male and four female PS (see Supplementary Fig. S1). Extractions were performed using Trizol (Invitrogen), with subsequent reprecipitation with $2 \mathrm{M} \mathrm{LiCl}$, then $0.3 \mathrm{M} \mathrm{NaOAc}$ and 2 vol EtOH (Sambrook and Russell 2001). The purity of our RNA was determined to be of a high level, as A260/A280 values were between 1.9 and 2.1. For synthesis of cDNA, $2.0 \mu \mathrm{g}$ of RNA was transcribed using the Qiagen Quantitect cDNA system, which includes an initial gDNA removal step. After gDNA removal, RNA concentration was calculated for each sample using a RiboGreen Assay, which enables accurate comparison of qRT-PCR samples without using a housekeeping gene for normalization (see below).

qRT-PCR experiments were performed with the iQ SYBR Green Supermix (BioRAD) with between 1.5 and 6.0 pmol of each primer. Amplification and detection of products was performed using the CFX96 Real Time System (BioRAD). The following thermoprofile was used for all qRT-PCR primer pairs (see Supplementary Table S1): $95^{\circ} \mathrm{C}$ for $10 \mathrm{~s}$ for 1 cycle; then $95^{\circ} \mathrm{C}$ for $5 \mathrm{~s}$, $60^{\circ} \mathrm{C}$ for $15 \mathrm{~s}, 72^{\circ} \mathrm{C}$ for $20 \mathrm{~s}$, for 44 cycles; then a melt curve from 60 to $95^{\circ} \mathrm{C}$ with $0.5^{\circ} \mathrm{C}$ increments for $5 \mathrm{~s}$ each.

Relative expression was calculated without a housekeeping gene comparison. This technique was used because we found that normalization to $\beta$-actin and gapdh gave conflicting results (data not shown). We employed the methods described in Cummings et al. (2008), using the formula $1 / E^{\mathrm{avgCT}}$, where $E=10^{- \text {(slope) }}$, as described in Simon (2003). Results were scaled against the RNA quantity calculated using the RiboGreen Assay and were compared using an independent $t$ test. We used a ShapiroWilk test for normality of our expression profiles (Shapiro and Wilk 1965) and found that all of the clones with significant $t$ test results were included in this list.

We obtained additional $3^{\prime}$-sequence of the clones that showed statistically significant expression difference using the forward primer designed for qRT-PCR or newly designed internal primers when the insert was long. These sequences were blasted in NCBI (using blastx, or tblastx and blastn when blastx did not deliver a significant result) on 16.08.09, and gene ontologies were searched using different databases and literature sources.

\section{Results}

When male skin was examined under transmitted light (Fig. 1c), we observed melanophores with melanosomes dispersed in the cells. Fewer melanophores were observed in the skin of the female of PS (Fig. 1d), but these looked very similar to the ones present in the males' skin. Furthermore, pterinosomes were also observed as yellow vacuoles under transmitted light, however, the whole xanthosome remained difficult to identify. No fluorescence was observed in the male's skin under UV light (Fig. 1e), suggesting that no or very few xanthophores are present in males. In the females' skin, we observed bright stains that autofluoresced against background under UV light (Fig. 1f). Some of these stains show the same pattern as the yellow vacuoles (Fig. 1d), but overall we observed many more of these stains in the picture under UV light than of yellow vacuoles (Fig. 1f).

In our analyses of the microarray experiments, we selected clones that displayed a greater than 2 -fold difference in terms of log ratios between the reference array and at least one of the two dye-flip arrays. We distinguished the selected clones, grouping them into three categories depending on the robustness of the data of the second dyeflip array. When the data showed a difference between log ratios of the intensities greater than 1.5-fold in both arrays, genes were grouped in category A. In the reverse case, i.e., if the difference between $\log$ ratios of the intensities of the second array was less than 1.5 -fold, clones were included in category B. Finally, category $\mathrm{C}$ contains genes selected in the absence of data for the second dye-flip experiment due to the presence of background dye on a particular spot.

We identified 46 clones, representing 45 unique sequences and tested their expression profiles with qRT-PCR in addition to csflra and csflrb. None of the control skin genes spotted onto the chip were included in this list. Of the 47 genes, 40 were successfully amplified and 5 were confirmed to display statistically significant expression differences in qRT-PCR experiments in PS (Table 1; Fig. 2). The one gene that could not be amplified was too short for satisfactory primers to be designed and was thus omitted from the analysis (21A E10). We found a relatively low concurrence between microarray and qRT-PCR results, which is likely to relate to an initially high false positive discovery rate in the microarray analysis and the use of new biological replicates in the qRT-PCR, as they were collected on a separate occasion compared to the pooled samples used in the microarray (see "Discussion" section). For some genes, we also found a very high level of variability between these biological replicates in the qRT-PCR (Supplementary Fig. S2), which would have been obscured by the pooled samples used in the microarray.

After additional sequencing, the genes could be further characterized by blast searches (Table 1). Initially, we used the blastx algorithm to query the $\mathrm{nr} / \mathrm{nt}$ nucleotide collection, and in the case that there was no significant hit, blastn 
Table 1 Clones selected after normalization of the microarrays and their top hits from the Genbank database, as determined through blastx, blastn, or tblastx

\begin{tabular}{|c|c|c|c|c|c|c|c|}
\hline \multirow[t]{2}{*}{ Clone } & \multicolumn{3}{|c|}{ Microarray log intensity values } & \multirow{2}{*}{$\begin{array}{l}\text { qRT-PCR } \\
P \text { value }\end{array}$} & \multicolumn{3}{|l|}{ BLAST identification } \\
\hline & Reference & Dye-flip a & Dye-flip b & & ID & Accession & E value \\
\hline \multicolumn{8}{|c|}{ Category A } \\
\hline 02A F10 & -3.444 & 0.314 & -2.687 & 0.408 & Defender against cell death 1 (DAD1) & ABD79023 & $4.00 \mathrm{E}-55$ \\
\hline 02B A11 & -4.092 & 0.770 & -2.847 & 0.784 & Annexin max 3 & NP_001098295 & $9.00 \mathrm{E}-90$ \\
\hline 03A A11 & 3.929 & 0.603 & 3.395 & 0.425 & No significant similarity & & \\
\hline 03A B02 & -2.797 & 0.567 & -1.841 & 0.889 & $60 \mathrm{~S}$ ribosomal protein L5 & ACI66198 & $8.00 \mathrm{E}-115$ \\
\hline 03A G01 & -1.793 & 1.232 & -2.872 & $0.012 *$ & Type 1 collagen alpha 2 & BAD77969 & $1.00 \mathrm{E}-144$ \\
\hline 03В В02 & -2.381 & 0.084 & -1.780 & 0.798 & $40 S$ ribosomal protein $\mathrm{S} 11$ & ACO15454 & $3.00 \mathrm{E}-81$ \\
\hline 04A F07 & 1.187 & -0.702 & 3.237 & 0.279 & Parvalbumin & ACF23534 & $8.00 \mathrm{E}-15$ \\
\hline 04C E05 & -2.626 & 0.541 & -1.172 & 0.268 & Parvalbumin & ADA70320 & $3.00 \mathrm{E}-44$ \\
\hline 11A G01 & -2.685 & 0.504 & -2.517 & 0.376 & Heat shock protein 90 beta & BAF92790 & $5.00 \mathrm{E}-92$ \\
\hline 11B A05 & 1.827 & -0.216 & 2.131 & 0.161 & Leucine zipper-EF-hand containing protein & XP_001251731 & $3.00 \mathrm{E}-13$ \\
\hline 11B A10 & -3.121 & -0.036 & -1.774 & 0.360 & $40 \mathrm{~S}$ ribosomal protein $\mathrm{SA}$ & ACO09157 & $4.00 \mathrm{E}-115$ \\
\hline 12B B04 & -3.767 & -0.519 & -36.175 & 0.741 & Major histocompatibility complex II & CAP47207 & $1.00 \mathrm{E}-19$ \\
\hline 12B E12 & -2.729 & 0.483 & -1.971 & 0.448 & Ribosomal protein L19 & CAD91441 & $7.00 \mathrm{E}-51$ \\
\hline $12 \mathrm{C} \mathrm{D} 12$ & -2.670 & 0.535 & -2.022 & 0.746 & No significant similarity & & \\
\hline 13B D03 & -2.561 & 0.670 & -2.979 & 0.246 & No significant similarity & & \\
\hline 13D H05 & -1.564 & 1.222 & -1.507 & 0.557 & Beta hemoglobin A & Q9PVM2 & $6.00 \mathrm{E}-67$ \\
\hline 14D D11 & -1.171 & 1.102 & -2.159 & 0.073 & Similar to Ribosomal protein L29 & XP_001151583 & $8.00 \mathrm{E}-24$ \\
\hline 18B H11 & -1.835 & 0.279 & -2.903 & 0.145 & No significant similarity & & \\
\hline csflra & & & & 0.261 & & & \\
\hline$c s f 1 r b$ & & & & 0.888 & & & \\
\hline \multicolumn{8}{|c|}{ Category B } \\
\hline 01A G09 & -2.354 & 0.169 & -1.404 & 0.980 & Ribosomal protein S14 & CAA69615 & $3.00 \mathrm{E}-73$ \\
\hline 01B B11 & -2.951 & -0.161 & -0.519 & 0.277 & Myosin light chain 2 & AAX34414 & $3.00 \mathrm{E}-04$ \\
\hline 01C G09 & -1.793 & 0.321 & -1.285 & 0.551 & Beta actin & AB037865 & 0 \\
\hline 03В В07 & -2.027 & 0.819 & -1.404 & 0.808 & Ubiquitin/ribosomal fusion protein & CAJ90900 & $9.00 \mathrm{E}-64$ \\
\hline 03C F01 & -2.252 & 0.291 & -1.221 & 0.413 & 40S ribosomal protein $\mathrm{S} 17$ & ACN09866 & $4.00 \mathrm{E}-67$ \\
\hline 03C H09 & -1.706 & 0.998 & -1.001 & 0.257 & Cold-shock domain protein & DQ840135 & 0 \\
\hline 03D A07 & -1.521 & 0.967 & -0.490 & 0.772 & $60 \mathrm{~S}$ ribosomal protein $\mathrm{L} 7 \mathrm{a}$ & ACQ59023 & $9.00 \mathrm{E}-21$ \\
\hline 11B E02 & -1.637 & 0.631 & -0.950 & 0.291 & Ribosomal protein S2 & BAF45464 & $2.00 \mathrm{E}-77$ \\
\hline 12A H03 & -1.834 & 1.439 & -1.406 & 0.515 & Thymosin beta- 4 putative & ВT082182 & $1.00 \mathrm{E}-87$ \\
\hline 12D F03 & -1.678 & 0.890 & -0.827 & 0.492 & Ribosomal protein L13a & BAF98661 & $1.00 \mathrm{E}-90$ \\
\hline 13C E01 & 0.237 & 0.155 & 2.443 & 0.142 & Fast/white muscle troponin $\mathrm{T}$ & ABF20456 & $1.00 \mathrm{E}-41$ \\
\hline 14C_E03 & -0.396 & 0.742 & 1.903 & & Parvalbumin 2 & ADA70320 & $2.00 \mathrm{E}-44$ \\
\hline 14C H09 & -1.080 & -1.102 & -2.476 & $0.045^{*}$ & Coatomer subunit zeta-1 & ACQ58956 & $2.00 \mathrm{E}-83$ \\
\hline 15A B05 & -1.112 & -0.422 & -2.451 & 0.502 & Collagen, type X, alpha 1 & ADG29155 & $2.00 \mathrm{E}-68$ \\
\hline 15A D07 & -1.196 & -0.458 & -21.025 & 0.211 & No significant match & & \\
\hline 17A E10 & 1.019 & -0.230 & 2.139 & $0.038^{*}$ & Tetraodon nigroviridis full-length cDNA & CR633442 & $8.00 \mathrm{E}-123$ \\
\hline 19A D07 & -1.787 & 0.255 & -0.402 & 0.947 & & & \\
\hline \multicolumn{8}{|c|}{ Category $C$} \\
\hline 03C D08 & 1.194 & $\mathrm{x}$ & -2.514 & 0.084 & No significant similarity & & \\
\hline 13C B02 & 1.096 & $\mathrm{x}$ & -1.869 & 0.976 & LINE partial sequence, clone:C8 & AB017056 & $7.00 \mathrm{E}-14$ \\
\hline 15B H02 & -1.387 & $\mathrm{x}$ & 1.247 & 0.183 & Adenylate kinase & CAG12406 & $2.00 \mathrm{E}-23$ \\
\hline $15 \mathrm{D}$ G03 & -1.000 & $\mathrm{x}$ & 1.236 & 0.123 & RAB11B, member RAS oncogene family & NP_001012569 & $5.00 \mathrm{E}-117$ \\
\hline 15D G09 & -1.548 & $\mathrm{x}$ & 1.231 & $0.039 *$ & No significant similarity & & \\
\hline 16D B11 & -1.452 & $\mathrm{x}$ & 1.026 & $0.041 *$ & No significant similarity & & \\
\hline
\end{tabular}


Table 1 continued

\begin{tabular}{|c|c|c|c|c|c|c|c|}
\hline \multirow[t]{2}{*}{ Clone } & \multicolumn{3}{|c|}{ Microarray $\log$ intensity values } & \multirow{2}{*}{$\begin{array}{l}\text { qRT-PCR } \\
P \text { value }\end{array}$} & \multicolumn{3}{|l|}{ BLAST identification } \\
\hline & Reference & Dye-flip a & Dye-flip b & & ID & Accession & E value \\
\hline 16D D05 & -1.444 & $\mathrm{x}$ & 1.308 & 0.198 & No significant similarity & & \\
\hline 19B E11 & -2.352 & 0.809 & $\mathrm{x}$ & 0.269 & Elongation factor $1 \mathrm{a}$ & BAB83860 & $3.00 \mathrm{E}-85$ \\
\hline 19C D03 & 1.080 & $\mathrm{x}$ & -1.503 & 0.265 & Calsequestrin 1 & AB442012 & $3.00 \mathrm{E}-139$ \\
\hline 20C F08 & -1.936 & $\mathrm{x}$ & 2.032 & 0.121 & No significant similarity & & \\
\hline
\end{tabular}

$* P<0.05$

and tblastx were used. For those with blast hits smaller than $1 \mathrm{e}^{-15}$, the name of the best hit will be used as an identifier in the remainder of the manuscript. We refer to genes as "similar to" when sequence similarities were greater than $1 \mathrm{e}^{-5}$ (Altschul et al. 1990). The list of five statistically significant genes includes Collagen 1 alpha, Coatomer protein complex, subunit, zeta-1 (Copz-1), one clone with a hit to the $3^{\prime}$-UTR of a ubiquitin-conjugating enzyme, and two clones without any annotation in the Genbank database (17A E10 and 16D B11). Both unannotated clones show strong hits to other cichlids in the BLAST EST database, and 17A E10 has significant hits to ESTs from other fish species. The clone 16D B11 had only a weak hit to the gilthead sea bream EST collection (Dicentrarchus labrax; $\mathrm{E}$ value $=0.005)$

\section{Discussion}

Here we assessed the level of expression of thousands of genes, to gain insight into the molecular pathways involved in the coloration of cichlid fish. Our microarray experiment highlighted 46 clones exhibiting differential expression between the two sexes of PS which, despite both having dark vertical stripes, differ greatly in coloration: females have yellow and males bright blue body colorations (Fig. 1a, b). Using qRT-PCR, we amplified 44 of the 46 clones identified in the microarray as well as csflra and csflrb. Of these, five are good candidates to study the molecular basis of sexual dimorphism in the skin of cichlids, as they have been confirmed to be differentially expressed between males and females (see Fig. 2).

\section{Coatomer Protein Complex, Subunit Zeta-1 (Copz-1)}

The resulting candidate gene list is composed of Collagen 1 alpha, Coatomer protein complex, subunit zeta-1 (Copz-1), one clone that matches to ubiquitin-conjugating enzyme in the $3^{\prime}$-UTR and two clones which do not have any annotated homologues. Copz-1 is currently the strongest candidate color gene derived from this study. Copz is a subunit of a protein complex that is a precursor of non-clathrin coated

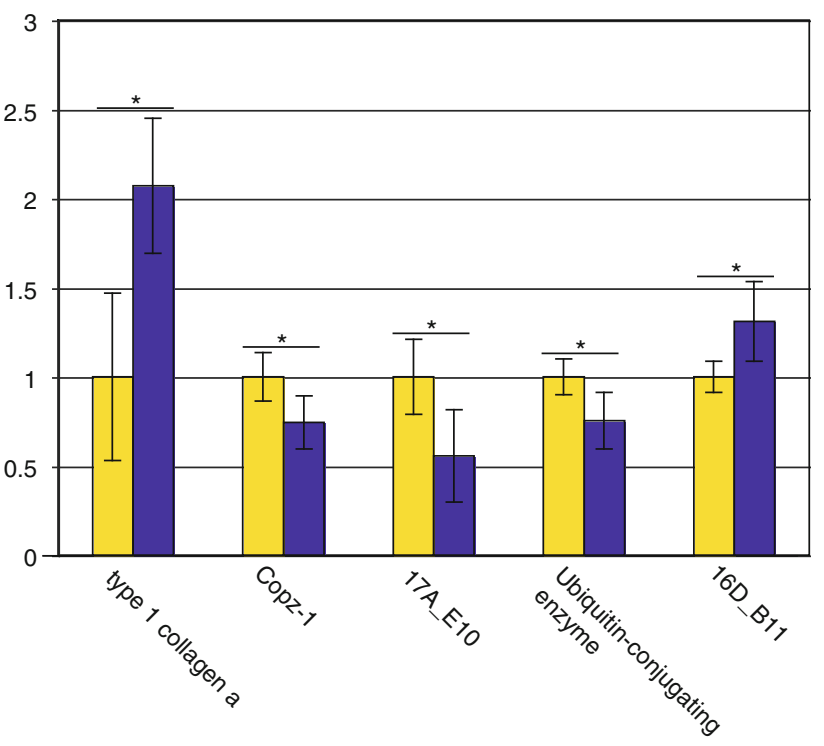

Fig. 2 Genes that differ in expression between males and females, as confirmed through qRT-PCR. The relative expression values are scaled so that female expression is equal to 1. Yellow bars represent PS female expression and blue bars represent the PS male $(* P<0.05)$

Golgi transport vesicles (Waters et al. 1991; Cosson et al. 1996; Moelleken et al. 2007). Previous data have established a connection between pigmentation and intracellular transport defects. Two human diseases, Chediak-Higashi syndrome and Hermansky-Pudlak syndrome, are characterized by albinism as well intracellular traffic disorders. In both diseases, cells exhibit abnormalities in endosomal/ lysosomal trafficking in various cytoplasmic organelles including melanosomes (Scriver 1995).

Copz is known to have a conserved role in pigmentation. In Drosophila, the altered expression of this gene has been shown to influence pigment granules of the eye (Scriver 1995). In addition, in zebrafish, Copz mutants show a reduction in the retinal pigmented epithelium (Gross et al. 2005). In addition, the mutation of three other vesicle trafficking genes in zebrafish is known to result in pronounced hypopigmentation as well as retinal defects (Maldonado et al. 2006). As it is thought that pigment granules are synthesized through transport between the 
endosome and the Golgi, Copz might be involved in the yellow coloration of female PS. The production of xanthophores requires the formation of a large number of vesicles for the synthesis and transport of pigments. Mutation of Copz in zebrafish does not result in measurably altered skin pigmentation. This implies that the putative role for Copz-1 in cichlid skin pigmentation arose in the lineage leading to the cichlid fishes, after its split from the lineage leading to the zebrafish.

\section{Collagen 1 alpha}

Collagen 1 alpha also represents a strong candidate for the sexual dimorphism in the skin of PS, albeit it is unlikely to be related to skin coloration. Collagen 1 alpha encodes a structural component of teleost skin and is known to be expressed in the skin of zebrafish throughout development (Le Guellec et al. 2004). Sexual dimorphism in skin thickness is observed in several teleost species (Smith 1978; Burton 1979; Pottinger and Pickering 1985), with the males displaying thicker epidermal and dermal layers due to elevated androgen levels. It is likely that the increased level of Collagen 1 alpha expression in the skin of male PS corresponds to a structural difference in the thickness of the epithelium.

We have successfully used microarray to identify promising candidates for sexually dimorphic coloration in cichlid fishes, however, we have met with some technical limitations that are likely to explain our low level of concurrence between the microarray and qRT-PCR data. For example, the use of a single array as a reference may have reduced the robustness of our study. Additionally, the inclusion of biological replication in our qRT-PCR analysis has highlighted that several of the genes in our list display variable levels of expression between individuals. In some cases, additional replicates might have increased the statistical power enough to identify significant differences; however, in other cases the variability is extremely high. This may be due to genuine biological differences, however, they are also likely to be confounded by minor differences in skin sampling regime, in which more or less of the underlying muscle may have been removed. Specifically, five clones (two parvalbumin orthologues, myosin light chain 2, fast/white muscle troponin $\mathrm{T}$ and 19C D03, which did not have a characterized orthologue) showed considerable differences in expression that related to individual sample, rather than sex (Supplementary Fig. S2). Their marked variability prevented a statistically significant result from being obtained and precludes them from being considered informative "color genes." Overall, these genes are over-expressed in female versus male samples, explaining their presence in the gene list derived from the microarray, which was based on pooled samples.
Interestingly, we did not detect differential expression of $c s f 1 r a$ and $c s f 1 r b$, which were initially included as positive controls. Strong expression of csflra has previously been demonstrated in newly formed egg dummies on the anal fins of cichlid fishes (Salzburger et al. 2007). Therefore, our results support the involvement of this gene in the specification of new xanthophores, but not their maintenance.

Our experiment has also revealed some limitations of expression profiling in skin samples. For example, we found that $\beta$-actin and gapdh gave inconsistent results when they were used for normalization. This may relate to either sex-biased expression of one of these genes, or minor differences in skin sampling regime, where one may inadvertently include a few muscle fibers along with the skin samples, and skew the expression of genes that are normally up-regulated in muscle cells (see Supplementary Fig. S2). It should be noted that in general it is challenging to obtain high-quality RNA from skin samples, due to the high proportion of inorganic material in the scales and due to difficulties in sampling all layers of skin while avoiding the underlying muscles. The difficulties we have encountered could have been minimized by taking samples from the caudal fin (which is also brightly colored), rather than from the flank. Indeed, this sampling regime has been employed successfully to examine the role of $\operatorname{Pax} 7$ in color patterning for various Lake Malawi cichlids (Roberts et al. 2009). Nevertheless, we have successfully employed a technique that removes the need for normalization, which appears to be a good choice for use in studies of non-model organisms that do not have confirmed control genes (Cummings et al. 2008).

\section{Conclusions}

We used complementary microarray techniques and qRTPCR experiments to discover novel candidate genes that underlie coloration in cichlids. Our study has identified several novel color gene candidates, the most promising of which is involved in endosome-to-Golgi trafficking. Future studies that investigate the function and regulation of these candidate genes will be required to further determine their exact role in pigmentation at the cellular and biochemical level.

Acknowledgments We thank E. Hespeler, J. Haugg, S. Kuraku, and H.-J. Lee for helpful suggestions on the manuscript and the other members of the Meyer-lab and especially Julia Jones for technical assistance. The reading of the arrays was performed at Altana Pharma, Konstanz, under the supervision of P. Hubert and A. Buhmann. This study was supported by the Zukunftskolleg of the University of Konstanz to H.G., by the Frauenfoerderung (University Konstanz) to C.C., by the Landesstiftung Baden-Württemberg, the 
Center for Junior Research Fellows (University Konstanz) and the EU (Marie Curie fellowship) to W.S., and grants of the Deutsche Forschungsgemeinschaft to A.M.

\section{References}

Abzhanov A, Kuo WP, Hartmann C, Grant R, Grant PR, Tabin CJ (2006) The calmodulin pathway and the evolution of elongated beak morphology in Darwin's finches. Nature 442:563-567

Albertson RC, Streelman JT, Kocher TD (2003) Directional selection has shaped the oral jaws of Lake Malawi cichlid fishes. Proc Natl Acad Sci USA 100:5252-5257

Allender CJ, Seehausen O, Knight ME, Turner GF, Maclean N (2003) Divergent selection during speciation of Lake Malawi cichlid fish inferred from parallel radiations in nuptial coloration. Proc Natl Acad Sci USA 100:14074-14079

Altschul SF, Gish W, Miller W, Myers EW, Lipmann DJ (1990) Basic local alignment search tool. J Mol Biol 215:403-410

Bagnara JT (1976) Colour change. In: Lofts B (ed) Physiology of the Amphibia. Academic Press, New York, NY, pp 1-52

Bagnara JT (1998) Comparative anatomy and physiology of pigment cells in nonmammalian tissues. In: Nordlund JJ (ed) The pigmentary system: physiology and pathophysiology. Oxford University Press, Oxford, pp 9-40

Bagnara JT, Hadley ME (1973) Chromatophores and color change: the comparative physiology of animal pigmentation. PrenticeHall, Englewood Cliffs, NJ

Bagnara JT, Stackhouse HL (1961) Purine components of guanophores in amphibians. Anat Rec 139:292

Bagnara JT, Matsumoto J, Ferris W, Frost SK, Turner WAJ, Tchen TT, Taylor JD (1979) Common origins of pigment cells. Science 203:410-415

Barlow GW, Rogers W, Cappeto RV (1977) Incompatibility and assortative mating in the Midas cichlid. Behav Ecol Sociobiol 2:49-59

Barlow GW, Francis RC, Baumgartner JV (1990) Do the colours of parents, companions and self influence assortative mating in the polychromatic Midas cichlid? Anim Behav 46:713-722

Birbeck MSC (1963) Electron microscopy of melanocytes: the fine structure of hair-bulb premelanophores. Ann N Y Acad Sci 100:540

Braasch I, Salzburger W, Meyer A (2006) Asymmetric evolution in two fish-specifically duplicated receptor tyrosine kinase paralogons involved in teleost colouration. Mol Biol Evol 23: 1192-1202

Braasch I, Schartl M, Volff J-N (2007) Evolution of pigment synthesis pathways by gene and genome duplication in fish. BMC Evol Biol 7:74

Braasch I, Volff J-N, Schartl M (2008) The evolution of teleost pigmentation and the fish-specific genome duplication. J Fish Biol 73:1891-1918

Braasch I, Liedtke D, Volff J-N, Schartl M (2009a) Pigmentary function and evolution of tyrp1 gene duplicates in fish. Pigment Cell Melanoma Res 22:839-850

Braasch I, Brunet F, Volff J-N, Schartl M (2009b) Pigmentation pathway evolution after whole-genome duplication in fish. Genome Biol Evol 1:479-493

Braasch I, Volff J-N, Schartl M (2009c) The endothelin system: evolution of vertebrate-specific ligand-receptor interactions by three rounds of genome duplication. Mol Biol Evol 26:783-799

Burton D (1979) Sexual dimorphism in the integumentary tissues of the threespine stickleback, Gasterosteus aculeatus from Leiurus. Copeia 3:533-555
Carelton KL, Spady TC, Streelman JT, Kidd MR, McFarland WN, Loew ER (2008) Visual sensitivities tuned by heterochronic shifts in opsin gene expression. BMC Biol 6:22

Charles A, Ingram JT (1959) Electron microscope observations of the melanocyte of the human epidermis. J Biophys Biochem Cytol 6:41-44

Cosson P, Démollière C, Hennecke S, Duden R, Letourneur F (1996) $\delta$ - and $\zeta$-COP, two Coatomer subunits homologous to clathrinassociated proteins, are involved in ER retrieval. EMBO $\mathrm{J}$ 15:1792-1798

Crawford DL, Pierce VA, Segal JA (1999) Evolutionary physiology of closely related taxa: analyses of enzyme expression. Am Zool 32:389-400

Cummings ME, Larkins-Ford J, Reilly CRL, Wong RY, Ramsey M, Hofmann HA (2008) Sexual and social stimuli elicit rapid and contrasting genomic responses. Proc R Soc Lond B 275:393-402

Drochmans P (1960) Electron microscope studies of epidermal melanocytes, and the fine structure of melanin granules. J Biophys Biochem Cytol 8:165-180

Elmer KR, Reggio C, Wirth T, Verheyen E, Salzburger W, Meyer A (2009a) Pleistocene desiccation in East Africa bottlenecked but not extirpate the adaptive radiation of Lake Victoria haplochromine cichlid fishes. Proc Natl Acad Sci USA 106:13404-13409

Elmer KR, Lehtonen TK, Meyer A (2009b) Color assortative mating contributes to sympatric divergence of neotropical cichlid fish. Evolution 63:2750-2757

Elmer KR, Kusche H, Lehtonen TK, Meyer A (2010) Local variation and parallel evolution: morphological and genetic diversity across a species complex of neotropical crater lake cichlids. Philos Trans R Soc B 365:1763-1782

Epperlein HH, Claviez M (1982) Changes in the distribution of melanophores and xanthophores in Triturus alpestris embryos during their transition from the uniform to banded pattern. Wilhelm Roux's Arch Dev Biol 192:5-18

Fang Y, Brass A, Hoyle DC, Hayes A, Bashein A, Oliver SG, Waddington D, Rattray M (2003) A model-based analysis of microarray experimental error and normalisation. Nucleic Acids Res 31:e96

Fryer G, Iles TD (1972) The cichlid fishes of the Great Lakes of Africa. T.H.F. Publications, Inc., Neptune City, NJ

Fujii R (1993a) Coloration and chromatophores. In: Evans DH (ed) The physiology of fishes. CRC Press, Boca Raton, FL, pp 535-562

Fujii R (1993b) Cytophysiology of fish chromatophores. Int Rev Cytol 143:191-255

Fujii R (2000) The regulation of motile activity in fish chromatophores. Pigment Cell Res 13:300-319

Galis F, Metz JAJ (1998) Why are there so many cichlid species? TREE 13:1-2

Gasch AP, Spellman PT, Kao CM, Carmel-Harel O, Eisen MB, Storz G, Botstein D, Brown PO (2000) Genomic expression programs in the response of yeast cells to environmental changes. Mol Biol Cell 11:4241-4257

Gross JM, Perkins BD, Amsterdam A, Egaña A, Darland T, Matsui JI, Sciascia S, Hopkins N, Dowling JE (2005) Identification of zebrafish insertional mutants with defects in visual system development and function. Genetics 170:245-261

Hama T (1963) The relation between the chromatophores and pterin compounds. Ann N Y Acad Sci 100:977-986

Hofmann CM, O'Quin KE, Marshall NJ, Cronin TW, Seehausen O, Carelton KL (2009) The eyes have it: regulatory and structural changes both underlie cichlid visual pigment diversity. PLoS Biol 7:e1000266

Kamei-Takeuchi I, Hama T (1971) Structural changes of pterinosome (pteridine pigment granule) during the xanthophore differentiation of Oryzias fish. J Ultrastruct Res 34:452-463 
Katagiri T, Asakawa S, Minagawa S, Shimizu N, Hirono I, Aoki T (2001) Construction and characterization of BAC libraries for three fish species; rainbow trout, carp and tilapia. Anim Genet 32:200-204

Knight ME, Turner GF, Rico C, van Oppen MJH, Hewitt GM (1998) Microsatellite paternity analysis on captive Lake Malawi cichlids supports reproductive isolation by direct mate choice. Mol Ecol 7:1605-1610

Kocher TD (2004) Adaptive evolution and explosive speciation: the cichlid fish model. Nat Rev Genet 5:288-298

Kocher TD, Lee WJ, Sobolewska H, Penman D, McAndrew B (1998) A genetic linkage map of a cichlid fish, the tilapia (Oreochromis niloticus). Genetics 148:1225-1232

Lang M, Miyake T, Braasch I, Tinnemore D, Siegel N, Salzburger W, Amemiya CT, Meyer A (2006) A BAC library of the East African haplochromine cichlid fish Astatotilapia burtoni. J Exp Zool B 306:35-44

Le Guellec D, Morvan-Dubios H, Sire J-Y (2004) Skin development in fish with particular emphasis on collagen deposition in the dermis of the zebrafish (Danio rerio). Int J Dev Biol 48:217-231

Maldonado E, Hernandez F, Lozano C, Castro ME, Navarro RE (2006) The zebrafish mutant $v p s 18$ as a model for vesicle-traffic related hypopigmentation diseases. Pigment Cell Res 19:315-326

Matsumoto J (1965a) Role of pteridines in the pigmentation of chromatophores in cyprinid fish. Jpn J Zool 14:45-94

Matsumoto J (1965b) Studies on fine structure and cytochemical properties of erythrophores in swordtail, Xiphophorus helleri, with special reference to their pigment granules (Pterinosomes). J Cell Biol 27:493-504

Matsumoto J, Kalishima T, Hama T (1960) Relation between the pigmentation and pterin derivatives of chromatophores during development in the normal black and transparent scaled types of goldfish (Carassius auratus). Genetics 45:1177-1189

Mellgren EM, Johnson SL (2002) The evolution of morphological complexity in zebrafish stripes. Trends Genet 18:128-134

Meyer A (1993) Phylogenetic relationships and evolutionary processes in East African cichlid fishes. Trends Ecol Evol 8:279-284

Meyer A, Kocher TD, Basasibwaki P, Wilson AC (1990) Monophyletic origin of Lake Victoria cichlid fishes suggested by mitochondrial DNA sequences. Nature 347:550-553

Michaut L, Flister S, Neeb M, White MP, Certa U, Gehring WJ (2003) Analysis of the eye developmental pathway in Drosophila using DNA microarrays. Proc Natl Acad Sci USA 100: 4024-4029

Moelleken J, Malsam J, Betts MJ, Movafeghi A, Reckmann I, Meissner I, Hellwig A, Russell RB, Söllner T, Brügger B, Wieland FT (2007) Differential localization of coatomer complex isoforms within the Golgi apparatus. Proc Natl Acad Sci USA 104:4425-4430

Obika M (1963) Association of pteridines with amphibian larva pigmentation and their biosynthesis in developing chromatophores. Dev Biol 6:99-112

Obika M (1993) Formation of pterinosomes and carotenoid granules in xanthophores of the teleost Oryzias latipes as revealed by the rapid-freezing and freeze-substitution method. Cell Tissue Res $271: 81-86$

Odenthal J, Rossnagel K, Haffter P, Kelsh RN, Vogelsang E, Brand M, van Eeden FJM, Furutani-Seiki M, Granato M, Hammerschmidt M, Heisenberg CP, Jiang YJ, Kane DA, Mullins MC, Nüsslein-Volhard C (1996) Mutations affecting xanthophore pigmentation in the zebrafish, Danio rerio. Development 123: 391-398

Parichy DM, Turner JM (2003) Temporal and cellular requirements for Fms signaling during zebrafish adult pigment pattern development. Development 130:817-833
Pottinger TG, Pickering AD (1985) Changes in skin structure associated with elevated androgen levels in maturing male brown trout, Salmo trutta L. J Fish Biol 26:745-753

Renn SCP, Aubin-Horth N, Hofmann HA (2004) Biologically meaningful expression profiling across species using heterologous hybridization to a cDNA microarray. BMC Genomics 5:1-13

Roberts RB, Ser JR, Kocher TD (2009) Sexual conflict resolved by invasion of a novel sex determiner in Lake Malawi cichlid fishes. Science 326:998-1001

Salzburger W, Meyer A (2004) The species flocks of East African cichlid fishes: recent advances in molecular phylogenetics and population genetics. Naturwissenschaften 91:277-290

Salzburger W, Mack T, Verheyen E, Meyer A (2005) Out of Tanganyika: genesis, explosive speciation, key-innovations and phylogeography of the haplochromine cichlid fishes. BMC Evol Biol 5:17

Salzburger W, Niederstätter H, Brandstätter A, Berger B, Parson W, Snoeks J, Sturmbauer C (2006) Colour-assortative mating among populations of Tropheus moorii, a cichlid fish from Lake Tanganyika, East Africa. Proc R Soc Lond B 273:257-266

Salzburger W, Braasch I, Meyer A (2007) Adaptive sequence evolution in a color gene involved in the formation of the characteristic egg-dummies of male haplochromine cichlid fishes. BMC Biol 5:51

Salzburger W, Renn SCP, Steinke D, Braasch I, Hofmann HA, Meyer A (2008) Annotation of expressed sequence tags for the East African cichlid fish Astatotilapia burtoni and evolutionary analyses of cichlid ORFs. BMC Genomics 9:96

Sambrook J, Russell DW (2001) Molecular cloning: a laboratory manual. Cold Spring Harbor Laboratory Press, Cold Spring Harbor, NY

Sanetra M, Henning F, Fukamachi S, Meyer A (2009) A microsatellite-based genetic linkage map of the cichlid fish, Astatotilapia burtoni (Teleostei): a comparison of genetic architectures among rapidly speciating cichlids. Genetics 182:387-397

Santini S, Boore JL, Meyer A (2003) Evolutionary conservation of regulatory elements in vertebrate Hox gene clusters. Genome Res 13:1111-1122

Sartor MA, Medvedovic M, Aronow BJ (2003) Microarray data normalization: the art and science of overcoming technical variance to maximize the detection of biological variance. In: Blalock EM (ed) A beginner's guide to microarray. Kluwer, Boston, pp 151-178

Scriver CR (1995) The metabolic and molecular basis of inherited disease. McGraw-Hill, New York

Seehausen O, van Alphen JJM (1999) Can sympatric speciation by disruptive sexual selection explain rapid evolution of cichlid diversity in Lake Victoria? Ecol Lett 2:262-271

Seehausen O, van Alphen JJM, Witte F (1997) Cichlid fish diversity threatened by eutrophication that curbs sexual selection. Science 277:1808

Seehausen O, Mayhew PJ, van Alphen JJM (1999) Evolution of colour patterns in East African cichlid fishes. J Evol Biol 12:514-534

Seehausen O, Terai Y, Magalhaes IS, Carleton KL, Mrosso HDJ, Miyagi R, van der Sluijs I, Schneider MV, Maan ME, Tachida H, Imai H, Okada N (2008) Speciation through sensory drive in cichlid fish. Nature 455:620-627

Segal E, Shapira M, Regev A, Pe'er P, Botstein D, Koller D, Friedman N (2003) Module networks: identifying regulatory modules and their condition-specific regulators from gene expression data. Nat Genet 34:166-176

Shapiro SS, Wilk MB (1965) An analysis of variance test for normality (complete samples). Biometrica 52:591-611

Simon P (2003) Q-Gene: processing quantitative real-time RT-PCR data. Bioinformatics 19:1439-1440 
Smith RJF (1978) Seasonal changes in the histology of the gonads and dorsal skin of the fathead minnow, Pimephales promelas. Can J Zool 56:2103-2109

Stiassny MLJ, Meyer A (1999) Cichlids of the Rift Lakes. Scientific American Magazine (February) 64-69

Streelmann JT, Albertson C, Kocher TD (2003) Genome mapping of the orange blotch colour pattern in cichlid fishes. Mol Ecol $12: 2465-2471$

Sturmbauer C, Meyer A (1992) Genetic divergence, speciation and morphological stasis in a lineage of African cichlid fishes. Nature 358:578-581

Taylor JS, Van de Peer Y, Meyer A (2001a) Revisiting a recent test of the ancient fish-specific genome duplication hypothesis. Curr Biol 11:R1005-R1007

Taylor J, Van de Peer Y, Braasch I, Meyer A (2001b) Comparative genomics provides evidence for an ancient genome duplication in fish. Philos Trans R Soc Lond B 356:1661-1679

van Oppen MJH, Turner GF, Rico C, Robinson RL, Deutsch JC, Genner MJ, Hewitt GM (1998) Assortative mating among rockdwelling cichlid fishes supports high estimates of species richness from Lake Malawi. Mol Ecol 7:991-1001

Verheyen E, Salzburger W, Snocks J, Meyer A (2003) The origin of the superflock of cichlid fishes from Lake Victoria, East Africa. Science 300:325-329
Watanabe M, Kobayashi N, Fujiyama A, Okada N (2003) Construction of a BAC library for Haplochromis chilotes, a cichlid fish from Lake Victoria. Genes Genet Syst 78:103-105

Watanabe M, Kobayashi N, Shin-i T, Horiike T, Tateno Y, Kohara Y, Okada N (2004) Extensive analysis of ORF sequences from two different cichlid species in Lake Victoria provides molecular evidence for a recent radiation event of the Victoria species flock: identity of EST sequences between Haplochromis chilotes and Haplochromis sp. "Redtailsheller". Gene 343:263-269

Waters MG, Serafini T, Rothman JE (1991) 'Coatomer': a cytosolic protein complex containing subunits of non-clathrin-coated Golgi transport vesicles. Nature 349:248-251

Whitehead A, Crawford DL (2005) Variation in tissue-specific gene expression among natural populations. Genome Biol 6:R13

Williams H, Brenner S, Venkatesh B (2002a) Characterization of the platelet-derived growth factor receptor alpha and c-kit genes in the pufferfish Fugu rubripes. DNA Seq 13:263-270

Williams H, Brenner S, Venkatesh B (2002b) Identification and analysis of additional copies of the platelet-derived growth factor receptor and colony stimulating factor 1 receptor genes in fugu. Gene 295:255-264 